\title{
REVIEW
}

\section{Evaluation and review of body fluids saliva, sweat and tear compared to biochemical hydration assessment markers within blood and urine}

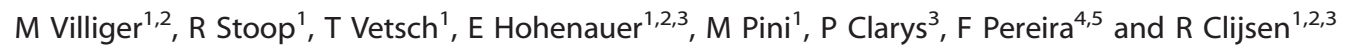

\begin{abstract}
Evaluating and testing hydration status is increasingly requested by rehabilitation, sport, military and performance-related activities. Besides commonly used biochemical hydration assessment markers within blood and urine, which have their advantages and limitations in collection and evaluating hydration status, there are other potential markers present within saliva, sweat or tear. This literature review focuses on body fluids saliva, sweat and tear compared to blood and urine regarding practicality and hydration status influenced by fluid restriction and/or physical activity. The selected articles included healthy subjects, biochemical hydration assessment markers and a well-described (de)hydration procedure. The included studies $(n=16)$ revealed that the setting and the method of collecting respectively accessing body fluids are particularly important aspects to choose the optimal hydration marker. To obtain a sample of saliva is one of the simplest ways to collect body fluids. During exercise and heat exposures, saliva composition might be an effective index but seems to be highly variable. The collection of sweat is a more extensive and time-consuming technique making it more difficult to evaluate dehydration and to make a statement about the hydration status at a particular time. The collection procedure of tear fluid is easy to access and causes very little discomfort to the subject. Tear osmolarity increases with dehydration in parallel to alterations in plasma osmolality and urine-specific gravity. But at the individual level, its sensitivity has to be further determined.
\end{abstract}

European Journal of Clinical Nutrition (2018) 72,69-76; doi:10.1038/ejcn.2017.136; published online 30 August 2017

\section{INTRODUCTION}

Human health and performance can be reduced when the body is dehydrated $^{1,2}$ and no gold standard for hydration assessment exists. ${ }^{3,4}$ Dehydration is a result of excess total body water (TBW) loss and is often accompanied by abnormalities in electrolyte balance. Heat, exercise-induced sweating or reduced thirst (often found in the elderly population) cause more water than sodium loss from the extracellular fluid (ECF) compartment, that is, hypertonic dehydration. Hypotonic dehydration shows more sodium than water loss and can be induced by diuretics or severely burned skin. Isotonic dehydration is caused by water and sodium loss in equivalent proportions such as during diarrhoea. ${ }^{5}$ When people exercise for longer periods without fluid replacement, whole-body dehydration is associated with reductions in plasma, interstitial and intracellular volume, that is, hypovolemia. ${ }^{6}$

Changes in body mass (BMc) are often used as measures of (de) hydration. This measurement is simple, inexpensive and noninvasive. Poorer memory and attention is observed with a BMc of $<1 \%{ }^{8}$ diminished physiological performance with a BMc of $>1-$ $2 \%^{9-14}$ and impaired endurance exercise performance with a dehydration threshold of $\geqslant 2 \% .{ }^{15}$ Measured fasting morning body mass is a reliable index of euhydration when assessed during 3-9 consecutive days, ${ }^{16,17}$ but the measurement of BMc has also some limitations. Measurements across the required 3-9 days are not always feasible (for example, availability) and for people participating in an exercise programme, body mass can change over time as a consequence of muscle hypertrophy independently of changes in body water or body fat loss. ${ }^{18}$ Thus, where it is not practical or possible to use repetitive measurements of body mass over time (monitoring), biochemical indices of hydration status based on concentration and composition of body fluids (that is, blood and urine) become a necessary alternative to evaluate body fluid balance. ${ }^{19}$

Blood plasma osmolality $\left(\mathrm{BP}_{\mathrm{osm}}\right.$-concentration of plasma, milliosmoles of solute particles per kilogram of water), plasma sodium concentration $\mathrm{BP}\left[\mathrm{Na}^{+}\right]$or blood serum osmolality $\left(\mathrm{BS}_{\text {osm }}\right)$ are regularly used blood markers for evaluating hydration status. $^{20-23}$ In this regard, when body fluids are steady and balanced, $\mathrm{BP}_{\text {osm }}$ combined with the TBW (fluid in intracellular and extracellular areas; approximately $0.6 \mathrm{I} / \mathrm{kg} \approx 63.3 \%$ of body mass) value describe the most accurate and exact hydration assessment values. ${ }^{3}$ But these hydration assessment techniques, such as stable isotope dilution and neutron activation analysis for TBW and $\mathrm{BP}_{\text {osm }}$, are time-consuming, expensive and invasive. Fluid concentrations are regulated in complex and dynamic processes. The intracellular fluid is measured indirectly by means of the assumption that the isotope distributes equally throughout intracellular fluid and $\mathrm{ECF}^{3}$ and that the hydration status is changed by volume and timing of water, sodium and osmolyte consumption. ${ }^{24}$

\footnotetext{
${ }^{1}$ Department of Business Economics, Health and Social Care, University of Applied Sciences and Arts of Southern Switzerland, Landquart/Manno, Switzerland; ${ }^{2}$ THIM University of Applied Sciences, Landquart, Switzerland; ${ }^{3}$ Department of Movement and Sport Sciences, Vrije Universiteit Brussel, Brussels, Belgium; ${ }^{4}$ Faculty of Medicine, Imperial College London, London, Great Britain and ${ }^{5}$ CSEM Centre Suisse d'Electronique et de Microtechnique SA, Landquart, Switzerland. Correspondence: Dr M Villiger, Department of Business Economics, Health and Social Care, University of Applied Sciences and Arts of Southern Switzerland, Weststrasse 8, Landquart 7302, Switzerland. 
As blood sampling is often difficult to execute in the field, evaluating hydration status in these settings include determination of urine osmolality $\left(U R_{\text {osm }}\right)$, urine-specific gravity $\left(U R_{s g}\right)$ and urine colour $\left.\left(U R_{\text {col }}\right)\right)^{25,26} U R_{s g}$ seems to be the most valid marker in the setting of dynamic (monitoring over time) dehydration assessment among these urinary markers. ${ }^{20}$

To be of practical use, measuring and evaluating hydration status should have the possibility to be used on a daily or even hourly basis. The ability to monitor hydration status has become increasingly studied within the rehabilitation, sport, military and performance-related activities. ${ }^{27-30}$ Besides $\mathrm{BMc}^{2} \mathrm{BP}_{\text {osm }}$ and $\mathrm{UR}_{\mathrm{sg}}$ seem to be the most effective markers to monitor hydration status among the aforementioned markers. ${ }^{20}$

There might be other potential biochemical markers present within saliva, sweat and tears being noninvasive 'freely accessible' body fluids. ${ }^{31,32}$ These markers can offer further in-depth knowledge of an individual's hydration status. On this basis, the interest of this review is to evaluate 'freely accessible' body fluids (saliva, sweat and tear) as hydration assessment markers compared to the aforementioned body fluids (blood: $\mathrm{BP}_{\mathrm{osm}}, \mathrm{BP}\left[\mathrm{Na}^{+}\right], \mathrm{BS}_{\text {osm }}$; urine: $\left.U_{\mathrm{osm}}, \mathrm{UR}_{\mathrm{sg}}, \mathrm{UR}_{\mathrm{col}}\right)$ during a well-described (de)hydration procedure influenced by fluid restriction and/or physical activity.

\section{MATERIALS AND METHODS}

Search strategy and selection process

A systematic search was accomplished in 2016 in the electronic databases MEDLINE (PubMed) and CENTRAL (Cochrane Library).

The following keywords and combinations using the Boolean formula AND/OR were used in PubMed without applying any automatic filters: (hydration OR dehydration [MeSH] OR hypernatremia $[\mathrm{MeSH}] \mathrm{OR}$ hyponatremia [MeSH] OR water loss [MeSH] OR body fluid balance [MeSH]) AND (saliva [MeSH] OR sweat [MeSH] OR tear [MeSH] OR axillary moisture OR skin temperature [MeSH] OR skin humidity $[\mathrm{MeSH}]$ OR skin water loss [MeSH] OR skin hydration) AND (body composition [MeSH] OR body weight [MeSH] OR body mass OR urine [MeSH] OR blood [MeSH]).

The following keywords and combinations were used in Cochrane Library (CENTRAL): dehydration AND saliva, dehydration AND sweat, dehydration AND tear, dehydration AND body weight and dehydration AND axillary moisture.

Records were excluded according to the below-mentioned inclusion/exclusion criteria. After removing all duplicates, titles and abstracts were checked by MV, RS, TV, EH, MP and RC. In addition, full texts of rejected records were randomly checked by the testers to ensure validity of the inclusion/exclusion criteria. Inclusion criteria for the articles were as follows: (1) randomized clinical or clinical trials, (2) English or German, (3) healthy humans regardless of age or physical performance ability, (4) biochemical hydration assessment markers (blood: $\mathrm{BP}_{\text {osm }}, \mathrm{BP}\left[\mathrm{Na}^{+}\right], \mathrm{BS}_{\text {osm }}$ and/ or urine: $U R_{\text {osm }}, U_{\text {sg, }}, U R_{\text {col }}$ ), (5) BMc and (6) 'freely accessible' and direct evaluation of body fluids (saliva, sweat, tear and axillary moisture) used as hydration assessment markers. In addition, the studies were checked for a well-described dehydration procedure (influenced by fluid restriction and/or physical activity).

Besides the search in the electronic databases, records were checked through links of related articles and references.

\section{Measurement equipment and quantity estimates}

For evaluating hydration status, osmolarity (mOsmol/l) and osmolality $(\mathrm{mOsmol} / \mathrm{kg}$ ) are mainly measured by freezing-point depression. ${ }^{20}$ The freezing points of solutions are lower with regard to a pure solvent and is directly proportional to the molality of the solute. Under the control of an osmometer, controller samples are allowed to melt relatively slowly and the freezing point can be determined: $\mathrm{BP}_{\text {osm }}$ : $275-295 \mathrm{mOsmol} / \mathrm{kg}$ (euhydrated), ${ }^{20,32-34} \mathrm{BS}_{\text {osm }}$ : 282-295 mOsmol/kg (euhydrated), ${ }^{35}$ and UR $\mathrm{Osm}_{\mathrm{m}}: \quad<700 \mathrm{mOsmol} / \mathrm{kg}$ (euhydrated). ${ }^{13,36}$
An ion-selective electrode measures the potential of a specific ion in solution (mmol/l): $B P\left[\mathrm{Na}^{+}\right]$: $135-145 \mathrm{mmol} / \mathrm{l}$ (euhydrated). ${ }^{22,23}$

Specific gravity $(\mathrm{g} / \mathrm{ml})$ is the ratio of the density of a substance to the density of a reference substance and is measured by a refractometer: $U_{\mathrm{sg}}:<1.010 \mathrm{~g} / \mathrm{ml}$ (euhydrated). ${ }^{13,14}$

The urine colour is measured by an ,8-point colour chart': $U_{\mathrm{col}}$ : 1 or 2 (euhydrated). ${ }^{14}$

\section{RESULTS}

In the Cochrane Library $n=388$ studies were recorded: dehydration AND body weight (279 hits), dehydration AND saliva (19 hits), dehydration AND sweat (75 hits), dehydration AND tear (15 hits), and dehydration AND axillary moisture (0 hits). In PubMed $n=312$ studies were found. After excluding records by duplicates and by not relevant titles, abstracts and full texts, 15 records met our inclusion criteria and one record was included through links of related articles (references). In summary, a total of $n=16$ studies was included in this review. Figure 1 presents the search strategy and selection process.

\section{Dehydration procedures}

In this section the dehydration procedures of the included studies of saliva (Table 1), sweat (Table 2) and tear are listed. To achieve an euhydrated state before testing all studies conducted a welldescribed hydration protocol. For a controlled dehydrated status, either a stationary cycle ergometer was used in an environmental chamber (saliva, ${ }^{20,28,36-38}$ sweat $^{19,39,40}$ and tear $^{27,31}$ ) or a treadmill (saliva $^{20,28,29,34,41}$ and sweat $^{34}$ ). Passive dehydration was either used with fluid restriction ${ }^{42,43}$ or extracellular dehydration using a loop diuretic (Furosemide). ${ }^{44}$ For comparison reasons, the results stand for the control/placebo groups to evaluate (de)hydration status.

Measurement equipment and direct fluid collection of saliva, sweat and tear

For most of the included studies, the measurement equipment to evaluate osmolarity and sodium concentration of saliva and sweat do not differ compared to the evaluation of blood and urine. ${ }^{19,20,28,29,34,36,37,39,40,42,44}$

Regarding saliva, Smith et al. ${ }^{41}\left(\mathrm{SA}_{\mathrm{osm}}\right.$ and $\mathrm{UR}_{\mathrm{osm}}$ : Fiske One-Ten Osmometer, Norwood, MA, USA; $\mathrm{BP}_{\text {osm }}$ : Model 3320 Osmometer)

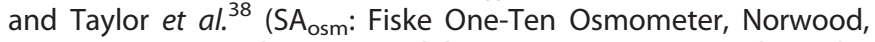
MA, USA; $\mathrm{BS}_{\text {osm }}$ and UR $\mathrm{R}_{\text {osm }}$ : Model 3250 Osmometer) used not the same osmometer to evaluate $\mathrm{SA}_{\text {osm }}, \mathrm{BP}_{\text {osm }}$ and $\mathrm{UR}_{\mathrm{osm}}$.

Saliva fluid. $\mathrm{SA}_{\mathrm{osm}}$ was measured after centrifugation by a freezing-point depression osmometer (for example, Fiske Associates, Fiske Micro-Osmometer, Model 210/Fiske One-Ten Osmometer ${ }^{20,28,38,41,44} /$ Advanced Instruments, Model 3320/Model $3 \mathrm{MO}$, Norwood, MA, USA ${ }^{29,36,37,42}$ ) and SA[Na+] was measured by an ion-selective electrode (Beckman Synchron El-ISE, Fullerton, CA, $\mathrm{USA}^{34}$ ). Direct collection of saliva samples is possible in two ways as described in the study by Ely et al. ${ }^{44}$

Saliva samples (expectorated ${ }^{20,28,44}$ ): Particiapnts were initially asked to swallow followed by a period of $2 \mathrm{~min}$ of passive saliva collection. The collected saliva was then expelled (spit) into a polypropylene Falcon tube (for example, Voigt Global Distribution, Inc., Lawrence, KS, USA).

Saliva samples (salivette $29,43,44)$ : Participants were asked to swallow before saliva collection. Saliva was collected with the use of a pre-weighed polyester salivette swab (for example, Sarstedt, Leics, UK) which was placed under the tongue for 2 min. During the collection period participants avoided any orofacial movements. To obtain salivary concentration samples, the participants were asked to accumulate saliva in their mouth (that is, passive 
drool technique) and finally expel around $1 \mathrm{ml}$ of saliva into a Dixie cup.

Sweat can be directly collected via two different techniques: (1) absorbancy method (i.e. sweat patch collection); and (2) wholebody washdown technique. ${ }^{34}$

(1) For the absorbancy method, the patch location was first cleaned (alcohol and distilled water) and then dried (air). Afterwards sweat patches were used where they were needed (for example, side-by-side to the upper back, just below the shoulder blades, to the forearm, chest and mid-thigh on the righthand side-the patches remained in place throughout the trial). ${ }^{34,40}$ Sweat was measured in small batches by for example a Cobas C311 module (Roche Diagnostics, Basel, Switzerland) using the ion-selective electrode technique for SW[Na ${ }^{+}$] (Easylyte Plus, Medica Corporation, Bedford, MA, USA, ${ }^{19}$ Beckman Synchron EI-ISE, Fullerton, CA, USA, 34 Beckman Instruments Inc., AS 80 System, Galway, Ireland ${ }^{39}$ ) or flame photometry (Sherwood, Cambridge, $\mathrm{UK}^{40}$ ).

(2) For the whole-body washdown technique, a kiddie pool placed in a fully enclosed walk-in tent was prepared in advance. After completion of the performance trial, each participant entered the plastic kiddie pool and approximately $1.5 \mathrm{I}$ of distilled water was poured over the participant's head and body. ${ }^{34}$ The participant was then asked to remove all clothing in the privacy of the tent and then pour the remaining amount of distilled water (3.78 I total) over his or her body. The removed clothes remained in the kiddy pool and to obtain water samples Eppendorf tubes were used.

Tear fluid was collected and analysed for $\mathrm{TE}_{\mathrm{osm}}$ using a commercially available diagnostic device (TearLab Osmolarity System; TearLab, San Diego, CA, USA). ${ }^{27,31}$ Participants blinked three times and squeezed their eyes shut. The released tear fluid from the lacrimal gland was immediately collected from the right eye using a handheld pen. A signal was transmitted when a sufficient volume $(50 \mathrm{nl})$ was collected, which typically took $<5 \mathrm{~s}$. Once docked on the Tearlab platform, the outcome was presented within $10 \mathrm{~s}$. BP $\mathrm{Bsm}_{\text {osm }}$ was measured by a freezing-point depression osmometer (Model 2020 27 /Model 330 MO,, ${ }^{31}$ Advanced Instruments).

\section{DISCUSSION}

The aim of the review was to evaluate 'freely accessible' and noninvasive body fluids (saliva, sweat and tear) compared to biochemical hydration assessment markers such as those within blood and urine during a well-described (de)hydration procedure influenced by fluid restriction and/or physical activity. First, the practical use of the different hydration assessment markers and, second, the results of saliva, sweat and tear body fluids are discussed regarding hydration status.

Practical use of body fluid hydration assessment markers

The measurement equipment for the evaluation of the hydration status change did not differ substantially between the included studies. This means that the underlying methods to evaluate osmolarity, osmomality ${ }^{20}$ and sodium concentration ${ }^{22}$ of body fluids were comparable. In this regard, not only the assessment technique itself but the procedure of collecting body fluids has a fundamental impact on the use of the biochemical hydration assessment markers. Collecting blood is an invasive procedure that makes it often difficult to execute in the field. Furthermore,

Records identified through database searching $(\mathrm{n}=700)$

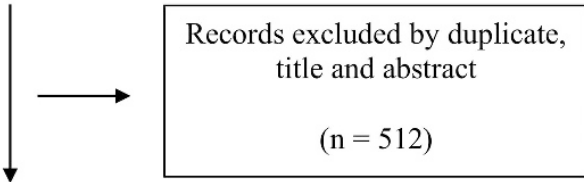

Full-text articles assessed for eligibility

$(\mathrm{n}=188)$

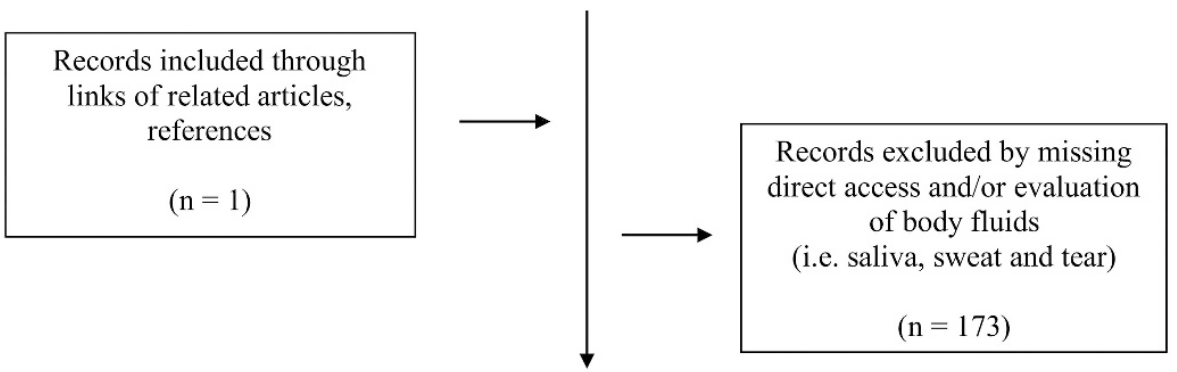

Studies included in review

$(\mathrm{n}=16)$

Figure 1. Flowchart of study screening and selection. 


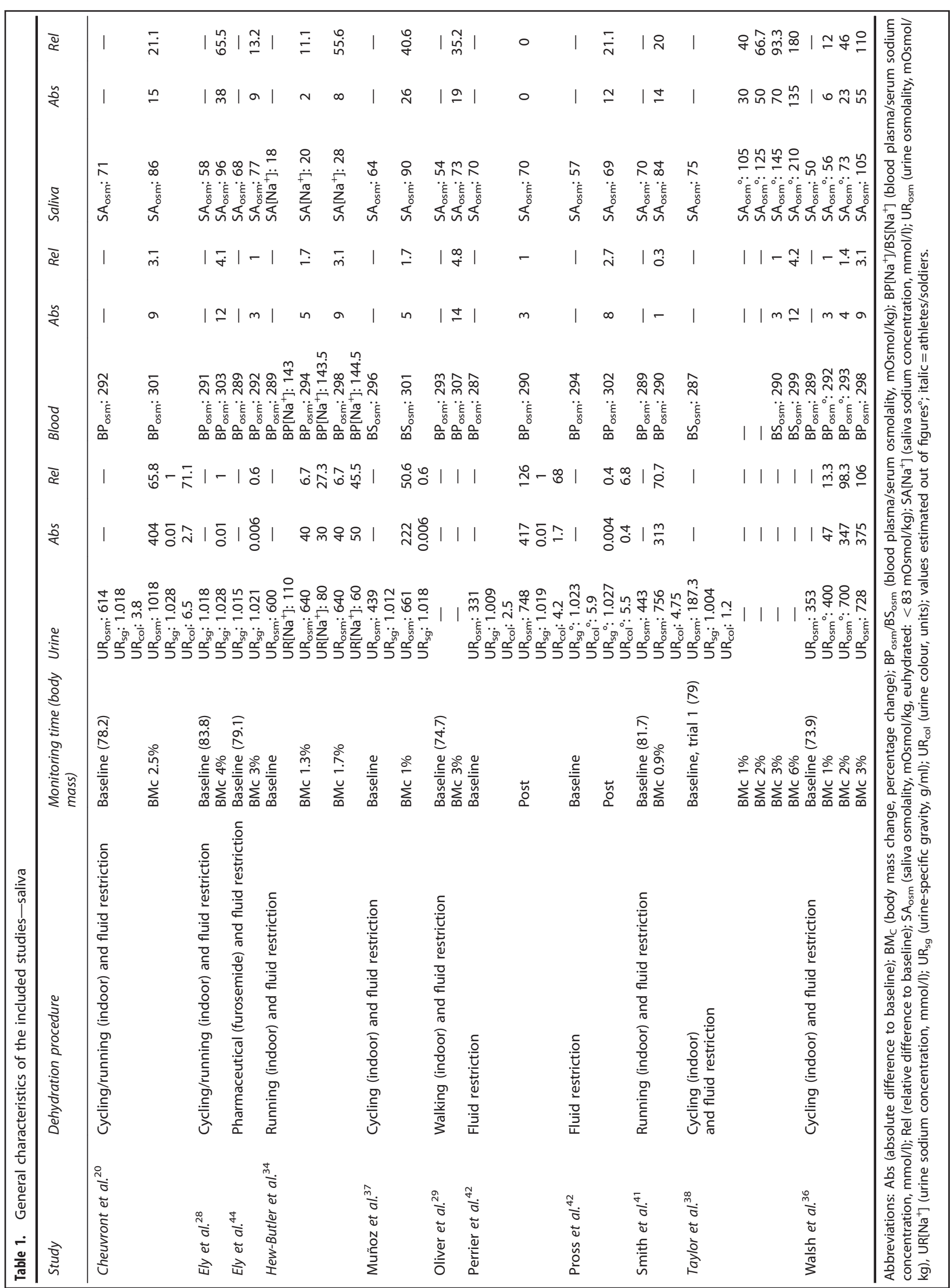


Table 2. General characteristics of the included studies-sweat

\begin{tabular}{|c|c|c|c|c|c|c|c|c|c|}
\hline Study & $\begin{array}{l}\text { Dehydration } \\
\text { procedure }\end{array}$ & $\begin{array}{l}\text { Monitoring time } \\
\text { (body mass) }\end{array}$ & Urine & Abs & Rel & Blood & Abs & Rel & Sweat \\
\hline \multirow[t]{2}{*}{ Hamouti et al. ${ }^{19}$} & \multirow[t]{2}{*}{$\begin{array}{l}\text { Cycling (indoor) and } \\
\text { fluid restriction }\end{array}$} & Baseline & $\begin{array}{l}\mathrm{UR}_{\text {osm }}{ }^{\circ}: 570 \\
\mathrm{UR}_{\mathrm{sg}} \mathrm{o}^{\circ}: 1.017 \\
\mathrm{UR}\left[\mathrm{Na}^{+}\right]: 79\end{array}$ & - & - & $\begin{array}{l}\mathrm{BS}_{\mathrm{osm}^{\circ}}: 282 \\
\mathrm{BS}\left[\mathrm{Na}^{+}\right]: 140.4\end{array}$ & - & - & - \\
\hline & & BMc 2\% & $\begin{array}{l}\mathrm{UR}_{\mathrm{osm}}{ }^{\circ}: 760 \\
\mathrm{UR}_{\mathrm{sg}}{ }^{\circ}: 1.023 \\
\left.\mathrm{UR}^{\mathrm{N}} \mathrm{Na}^{+}\right]: 73.9\end{array}$ & $\begin{array}{c}190 \\
0.006 \\
5.1\end{array}$ & $\begin{array}{c}33.3 \\
0.6 \\
93.5\end{array}$ & $\begin{array}{l}\mathrm{BS}_{\mathrm{osm}^{\circ}}: 292 \\
\mathrm{BS}\left[\mathrm{Na}^{+}\right]: 143.1\end{array}$ & $\begin{array}{l}10 \\
2.7\end{array}$ & $\begin{array}{l}103.5 \\
101.9\end{array}$ & SW[Na $\left.{ }^{+}\right]: 65$ \\
\hline \multirow[t]{3}{*}{ Hew-Butler et al. ${ }^{34}$} & \multirow[t]{3}{*}{$\begin{array}{l}\text { Running (indoor) } \\
\text { and fluid restriction }\end{array}$} & Baseline & $\begin{array}{l}\text { UR } \\
\text { URm: } 600 \\
\left.\text { URa }{ }^{+}\right]: 110\end{array}$ & - & - & $\begin{array}{l}\mathrm{BP}_{\text {osm }}: 289 \\
\left.\text { BP[Na }{ }^{+}\right]: 143\end{array}$ & - & - & - \\
\hline & & BMc 1.3\% & $\begin{array}{l}\text { UR } \\
\text { osm: } 640 \\
\left.\text { UR[Na }{ }^{+}\right]: 80\end{array}$ & $\begin{array}{l}40 \\
30\end{array}$ & $\begin{array}{c}6.7 \\
27.3\end{array}$ & $\begin{array}{l}\mathrm{BP}_{\text {osm }}: 294 \\
\left.\text { BP[Na }{ }^{+}\right]: 143.5\end{array}$ & $\begin{array}{c}5 \\
0.5\end{array}$ & $\begin{array}{c}1.7 \\
100.3\end{array}$ & $\mathrm{SW}\left[\mathrm{Na}^{+}\right]: 80$ \\
\hline & & BMc $1.7 \%$ & $\begin{array}{l}\text { UR } \\
\text { URm }: 640 \\
\text { URa }\left[\mathrm{Na}^{+}\right]: 60\end{array}$ & $\begin{array}{l}40 \\
50\end{array}$ & $\begin{array}{l}6.7 \\
45.5\end{array}$ & $\begin{array}{l}\mathrm{BP}_{\mathrm{osm}}: 298 \\
\left.\text { BP[Na }{ }^{+}\right]: 144.5\end{array}$ & $\begin{array}{c}9 \\
1.5\end{array}$ & $\begin{array}{l}3.1 \\
1.0\end{array}$ & $\mathrm{SW}\left[\mathrm{Na}^{+}\right]: 80$ \\
\hline \multirow[t]{3}{*}{ Morgan et al. ${ }^{40}$} & \multirow[t]{3}{*}{$\begin{array}{l}\text { Cycling (indoor) and } \\
\text { fluid restriction }\end{array}$} & Baseline (78.7) & - & - & - & 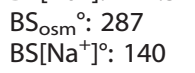 & - & - & - \\
\hline & & Post $60 \mathrm{~min}$ & - & - & - & 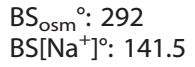 & $\begin{array}{c}5 \\
1.5\end{array}$ & $\begin{array}{l}1.7 \\
1.1\end{array}$ & - \\
\hline & & Post $120 \mathrm{~min}$ & - & - & - & 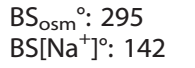 & $\begin{array}{l}8 \\
2\end{array}$ & $\begin{array}{l}2.8 \\
1.4\end{array}$ & $\begin{array}{l}\text { SW } \text { osm }: 172 \\
\left.\text { SW[Na }{ }^{+}\right]: 91.1\end{array}$ \\
\hline Walsh et al. ${ }^{39}$ & $\begin{array}{l}\text { Cycling (indoor) and } \\
\text { fluid restriction }\end{array}$ & $\begin{array}{l}\text { BMc: } 1.8 \% \\
\text { Post } 60 \mathrm{~min}\end{array}$ & UR[Na $\left.{ }^{+}\right]: 9.9$ & - & - & - & - & - & $\mathrm{SW}\left[\mathrm{Na}^{+}\right]: 108.9$ \\
\hline
\end{tabular}

Abbreviations: Abs (absolute difference to baseline); $\mathrm{BM}_{\mathrm{C}}$ (body mass change, percentage change); $\mathrm{BP}_{\text {osm }} / \mathrm{BS}_{\text {osm }}$ (blood plasma/serum osmolality, $\mathrm{mOsmol} / \mathrm{kg}$ ); $\mathrm{BP}\left[\mathrm{Na}^{+}\right] / \mathrm{BS}\left[\mathrm{Na}^{+}\right]$(blood plasma/serum sodium concentration, $\left.\mathrm{mmol} / \mathrm{l}\right) ;$ Rel (relative difference to baseline); $\mathrm{SW}_{\text {osm }}$ (sweat osmolality, $\mathrm{mOsmol} / \mathrm{kg}$ ), SW[Na $\left.{ }^{+}\right]$ (sweat sodium concentration, $\mathrm{mmol} / \mathrm{l}) ; \mathrm{UR}_{\mathrm{osm}}$ (urine osmolality, $\mathrm{mOsmol} / \mathrm{kg}$ ); $\mathrm{UR}\left[\mathrm{Na}^{+}\right]$(urine sodium concentration, $\left.\mathrm{mmol} / \mathrm{l}\right) ; \mathrm{UR}_{\mathrm{sg}}$ (urine-specific gravity, $\mathrm{g} / \mathrm{ml}$ ); values estimated out of figures ${ }^{\circ}$; italic $=$ athletes/soldiers.

$\mathrm{BP}_{\mathrm{osm}}$ and $\mathrm{BS}_{\mathrm{osm}}$ are tightly regulated in the brain. They are not good indices of the hydration status across days but across hours, because the kidneys constantly attempt to bring tonicity back below $296 \mathrm{mOsmol} / \mathrm{kg}^{45}$

Urine collection is a noninvasive method. A limiting factor during the dehydration process is the availabilty of urine (for example, bladder voiding is not always feasible). Measuring $U_{\mathrm{sg}}$ with a refractometer is less subjective than $U R_{c o l}$ as well as simple to use. ${ }^{14}$ Although $U_{R_{\text {osm }}} U_{\text {sg }}$ and $U_{\text {col }}$ have been suggested for screening older adults for dehydration, their diagnostic accuracy is too marginal to be beneficial. ${ }^{46}$ In addition, a dehydration procedure for older adults is not reasonable. Compared to blood and urine, saliva samples can always be directly collected and are always available. But saliva markers seem to be highly variable between subjects (see below). Futhermore, there are two possible techniques to collect sweat-the absorbancy method (that is, sweat patch collection) or the whole-body washdown technique. ${ }^{34}$ Compared to the collection of the other body fluids both techniques provide no baseline measurement. The collection of sweat is time-consuming and the sweating protocol only practicable in sweating-related activities rather than rehabilitation or nursing setting. Although only two studies with the collection procedure of tear fluid were included in this review, the procedure shows a promising result. The collection of tear fluid causes little discomfort to the subject and a sample is always obtained. ${ }^{27,31}$

The interested reader with regard to cost efficiency, time efficiency, simplicity of test and scientific value of hydration assessment markers is directed elsewhere. ${ }^{47}$

\section{Saliva and hydration status}

Saliva is made up mostly of water (97-99.5\%) originating from plasma via acinar cells. ${ }^{48}$ The accumulation of primary saliva is supported by the transacinar cell sodium gradient from plasma through acinar cells. The ECF sodium concentration increases and this is reflected in an increase in $\mathrm{BP}_{\text {osm }}$ during hypertonichypovolemia dehydration what might be linked with the secretion of more concentrated saliva with a decrease in TBW. ${ }^{36} \mathrm{SA}_{\mathrm{osm}}$ has been shown to increase with progressive dehydration, ${ }^{28,36,38}$ fluid deprivation and restriction. ${ }^{29,43}$ Furthermore, to record alterations during hypertonic-hypovolemia dehydration, $\mathrm{SA}_{\text {osm }}$ might be as sensitive as $U_{\mathrm{osm}_{\mathrm{om}}}$. Given that a fluid intake of 1.0 I per day seems to be insufficient to compensate water losses during the day, ${ }^{49}$ it was assumed that there would be differences between the low and high fluid intake regarding $\mathrm{SA}_{\mathrm{osm}}{ }^{42}$ However, no differences in $\mathrm{SA}_{\text {osm }}$ were reported by Perrier et al. ${ }^{42}$ In this regard $\mathrm{SA}_{\text {osm }}$ was highly variable between participants as also shown in prior studies. ${ }^{28,36}$

During active heat exposure in the study by Muñoz et al., ${ }^{37}$ $\mathrm{BS}_{\text {osm }}$ and $\mathrm{SA}_{\text {osm }}$ were the most effective hydration assessment markers (that is, high specificity and sensitivity). Further, for single measurements, $\mathrm{BS}_{\text {osm }}$ and $\mathrm{SA}_{\text {osm }}$ propose good usability during high temperature and exercise. For measurements over time $\mathrm{BS}_{\mathrm{osm}}, \mathrm{UR}_{\mathrm{sg}}$ and $\mathrm{BMc}$ seem to be the most valid hydration assessment markers. In this regard, Cheuvront et al. ${ }^{20}$ suggest that $\mathrm{BP}_{\mathrm{osm}}, \mathrm{UR}_{\mathrm{sg}}$ and $\mathrm{BMc}$ are appropriate markers during dynamic (monitoring over time) dehydration but only $\mathrm{BP}_{\text {osm }}$ (not $\mathrm{SA}_{\text {osm }}$ ) as useful marker for static (one time) dehydration assessment.

There were weak significant correlations reported between SA $\left[\mathrm{Na}^{+}\right]$and $\mathrm{BP}\left[\mathrm{Na}^{+}\right](r=0.45)$. Thus, the use of saliva provides limited support as a potential substitute for reporting changes in $\mathrm{BP}\left[\mathrm{Na}^{+}\right]$ in real time ${ }^{36}$ during exercise, ${ }^{37}$ probably because of reduced parasympathetic stimuli that alter secretion rates of saliva. ${ }^{37}$ However, the difference between $\mathrm{BP}\left[\mathrm{Na}^{+}\right]$and $\mathrm{SA}\left[\mathrm{Na}^{+}\right]$was approximately sevenfold.

Sweat and hydration status

In a hot environment or during exercise, body temperature is controlled by the evaporation of sweat. The deficit in electrolytes can be preserved by means of sodium reabsorption from the duct of sweat glands. Evidence supporting blood osmolality as a hydration assessment marker usually comes from studies that integrate a sweat-loss model of hypertonic-hypovolemia in young, fit and healthy individuals. In this regard, blood osmolality is unsuitable to detect isotonic-hypovolemia often following from illness and medications (for example, diuretics) in a clinical setting. ${ }^{47}$ 
Table 3. General characteristics of the included studies-tear

\begin{tabular}{|c|c|c|c|c|c|c|c|c|c|c|c|}
\hline Study & Dehydration procedure & Monitoring time (body mass) & Urine & Abs & Rel & Blood & Abs & Rel & Tear & Abs & Rel \\
\hline \multirow[t]{5}{*}{ Fortes et al. ${ }^{31}$} & \multirow{5}{*}{$\begin{array}{l}\text { Cycling (indoor) } \\
\text { and fluid restriction }\end{array}$} & Baseline (68.1) & $\mathrm{UR}_{\mathrm{sg}}{ }^{\circ}: 1.006$ & - & - & $\mathrm{BP}_{\text {osm }}: 288$ & - & - & $\mathrm{TE}_{\mathrm{osm}}: 293$ & - & \\
\hline & & BMc 1\% & $\mathrm{UR}_{\mathrm{sg}}{ }^{\circ}: 1.008$ & 0.002 & 0.2 & $\mathrm{BP}_{\mathrm{osm}}{ }^{\circ}: 289$ & 1 & 0.3 & $\mathrm{TE}_{\mathrm{osm}}^{\circ}: 299$ & 6 & 2 \\
\hline & & BMc $2 \%$ & $\mathrm{UR}_{\mathrm{sg}}{ }^{\circ}: 1.017$ & 0.011 & 1.1 & BP osm $: 292$ & 3 & 1.4 & $\mathrm{TE}_{\mathrm{osm}}{ }^{\circ}: 300$ & 7 & 2.4 \\
\hline & & BMc 3\% & $U_{\mathrm{sg}}: 1.021$ & 0.015 & 1.5 & BP osm: 297 & 9 & 3.1 & $\mathrm{TE}_{\mathrm{osm}}^{\circ}: 305$ & 12 & 4.1 \\
\hline & & BMc (overnight) 3.5\% & $\mathrm{UR}_{\mathrm{sg}}: 1.026$ & 0.02 & 2 & $\mathrm{BP}_{\text {osm }}: 297$ & 9 & 3.1 & $\mathrm{TE}_{\mathrm{osm}}: 304$ & 11 & 3.8 \\
\hline \multirow[t]{4}{*}{ Ungaro et al. ${ }^{27}$} & \multirow{4}{*}{$\begin{array}{l}\text { Cycling (indoor) } \\
\text { and fluid restriction }\end{array}$} & Baseline (75.7) & $U R_{s g}{ }^{\circ}: 1.006$ & - & - & $\mathrm{BP}_{\mathrm{osm}}^{\circ}: 292$ & - & - & $\mathrm{TE}_{\mathrm{osm}}^{\circ}: 296$ & - & - \\
\hline & & BMc $1 \%$ & $U_{\mathrm{sg}}: 1.012$ & 0.006 & 0.6 & $\mathrm{BP}_{\text {osm }}: 293$ & 1 & 0.3 & TE $_{\text {osm }}: 299$ & 3 & 1 \\
\hline & & BMc $2 \%$ & $\mathrm{UR}_{\mathrm{sg}}: 1.020$ & 0.014 & 1.4 & $\mathrm{BP}_{\text {osm }}: 295$ & 3 & 1 & $\mathrm{TE}_{\mathrm{osm}}: 301$ & 5 & 1.7 \\
\hline & & BMc 3\% & $\mathrm{UR}_{\mathrm{sg}}: 1.021$ & 0.015 & 1.5 & $\mathrm{BP}_{\text {osm }}: 297$ & 5 & 1.7 & $\mathrm{TE}_{\mathrm{osm}}: 302$ & 6 & 2 \\
\hline
\end{tabular}

Abbreviations: Abs (absolute difference to baseline); $\mathrm{BM}_{\mathrm{C}}$ (body mass change, percentage change); $\mathrm{BP}_{\mathrm{osm}}$ (blood plasma osmolality, $\mathrm{mOsmol} / \mathrm{kg}$ ); Rel (relative difference to baseline); $\mathrm{TE}_{\mathrm{osm}}$ (tear osmolarity, $\mathrm{mOsmol} / \mathrm{l}$, euhydrated: $\left.<310 \mathrm{mOsmol} / \mathrm{l}\right) ; \mathrm{UR}_{\mathrm{sg}}$ (urine-specific gravity, $\mathrm{g} / \mathrm{ml}$ ); values estimated out of figures; italic $=$ athletes.

Hew-Butler et al. ${ }^{34}$ utilized both abovementioned techniques to quantify changes in SW[Na ${ }^{+}$. But the lack to detect small, realtime, regulatory variations in sweat gland output limits the study. However, SW[Na $\left.{ }^{+}\right]$values were sevenfold less than the patch collection (between 12 and $14 \mathrm{mmol} / \mathrm{l}$ ) and $~ 50 \%$ less than those previously indicated. The differences between the absorbancy method and the whole-body washdown technique results may be due to missed collection of sweat, captured electrolytes in clothes and/or collection area, or contamination from other solutions.

A further limitation of the collection of sweat is the missing baseline value. To compare a dehydrated with an euhydrated status, Morgan et al. ${ }^{40}$ tested participants ingesting either no fluid (dehydration) or a $20 \mathrm{mmol} / \mathrm{l}$ sodium chloride solution (euhydration) during exercise. They showed that dehydration caused an increase in SW[Na $\left.{ }^{+}\right]$with regard to an euhydrated state. It is proposed that differences between dehydration and euhydration in $\mathrm{ECF}\left[\mathrm{Na}^{+}\right]$, acute aldosterone and sympathetic nervous activity could cause the changed sweat composition. Both $\mathrm{BS}\left[\mathrm{Na}^{+}\right]$and SW $\left[\mathrm{Na}^{+}\right]$were higher in a dehydrated state. ${ }^{40}$ When the subjects were dehydrated due to higher $\mathrm{BS}\left[\mathrm{Na}^{+}\right]$, it is predicted by Morgan et al. $^{40}$ that an increased sodium concentration would have appeared in the primary sweat. However, the difference between dehydration and euhydration for $\mathrm{BS}\left[\mathrm{Na}^{+}\right]$was approximately $3 \mathrm{mmol} / \mathrm{l}$, which was lower than that found in sweat, which was $\sim 10 \mathrm{mmol} / \mathrm{l}$. Therefore, a simple displacement into primary sweat, resulting from the greater $\mathrm{ECF}\left[\mathrm{Na}^{+}\right]$could not solely account for the higher $S W\left[\mathrm{Na}^{+}\right]$. A second possible explanation for the increase in $\mathrm{SW}\left[\mathrm{Na}^{+}\right]$during dehydration could have been an influence of elevated aldosterone on the secretory coil. A third explanation for the increase in SW[Na $\left.{ }^{+}\right]$could also have been an augmented activity of the sympathetic nervous system. During exercise-induced dehydration, the calculated ECF volume by Hamouti et al. ${ }^{19}$ declined progressively from exercise-baseline value likely due to water losses through sweating while $\mathrm{BS}_{\text {osm }}$ increased. Furthermore, SW $\left[\mathrm{Na}^{+}\right]$losses, as a result of a higher SW $\left[\mathrm{Na}^{+}\right]$concentration, can significantly affect post-race $\mathrm{BS}\left[\mathrm{Na}^{+}\right]$ concentration in long-runners, ${ }^{50}$ and $\mathrm{SW}\left[\mathrm{Na}^{+}\right]$did not reflect the same pattern as UR[Na+ ${ }^{34}$

Tear and hydration status

Tear fluid is a complex solution intended to sustain the surface of the eye. ${ }^{51}$ The lacrimal gland secretes tear fluid consisted mainly of water and electrolytes, and human tears have been disclosed to be isotonic with plasma. ${ }^{52}$

$\mathrm{TE}_{\mathrm{osm}}$ increased with dehydration and tracked changes in $\mathrm{BP}_{\mathrm{osm}}$ and $U_{\text {sg }}$, and therefore it might offer a new hydration assessment technique in rehabilitation, sport, military and performancerelated activities. $\mathrm{TE}_{\mathrm{osm}}$ can record alterations in hydration status due to water consumption during progressive rehydration following exercise as well as differentiate between dehydration
(2-3\% BMc) and euhydration during exercise. ${ }^{27}$ It seems that $\mathrm{BP}_{\text {osm }}$ and $\mathrm{TE}_{\mathrm{osm}}$ have the strongest correlation over the other widely used hydration assessments (eg. $B M c, U_{\text {sg }}$ ).

It is suggested that a $\mathrm{TE}_{\mathrm{osm}}$ value $>309 \mathrm{mOsmol} / \mathrm{l}$ reflects dehydration. ${ }^{31}$ This value was not reached in the two included studies but increases in $\mathrm{BP}_{\text {osm }}$ during exercise-evoked dehydration $^{27,31}$ and subsequent overnight fluid restriction ${ }^{31}$ were represented in increases in $\mathrm{TE}_{\mathrm{osm}}$. The data indicate that $\mathrm{TE}_{\mathrm{osm}}$ was 5-10 mOsmol higher than the respective $\mathrm{BP}_{\text {osm }}$ (Table 3 ). The $\mathrm{BP}_{\text {osm }}$ cutoff for minimal dehydration is $295 \mathrm{mOsmol} / \mathrm{kg}^{14}$ Compared with the $\mathrm{TE}_{\mathrm{osm}}$ values, $301 \mathrm{mOsmol} / \mathrm{l}$ could be the cutoff value for a minimally dehydrated status. It has to be taken into account that $\mathrm{TE}_{\mathrm{osm}}$ was measured as osmolarity' (number of osmoles of solute per liter of solution) and $\mathrm{BP}_{\text {osm }}$ was measured as osmolality' (number of osmoles of solute per kilogram of solvent). Furthermore, in the response of $\mathrm{TE}_{\mathrm{osm}}$ to changes in hydration status, there are large differences among subjects limiting its validity and usefulness at the individual level. The potential usefulness of $\mathrm{TE}_{\mathrm{osm}}$ to estimate hydration status at the individual level has to be further determined as well as how its validity and reliability are impacted by field conditions. ${ }^{27}$ Nevertheless, it can be suggested that $\mathrm{TE}_{\mathrm{osm}}$ has utility as a marker of hydration status (strong correlation between $\mathrm{TE}_{\mathrm{osm}}$ and $\mathrm{BP}_{\text {osm }}: r=0.93$ ). The correlation between $\mathrm{TE}_{\mathrm{osm}}$ and $\mathrm{BP}_{\mathrm{osm}}$ was even stronger than that between $U_{\text {sg }}$ and $\mathrm{BP}_{\text {osm }}(r=0.72) .^{31}$

\section{Dehydration and hyperthermia}

Trangmar and González-Alonso ${ }^{6}$ showed that progressive exercise-induced dehydration, with concomitant hyperthermia, can be associated with impaired perfusion to tissues and organs. In most included studies, the combination of exercise-induced dehydration and heat stress was presented, which makes it difficult to separate the effects of dehydration and hyperthermia in each compartment. ${ }^{53}$ It is well known that hyperthermia negatively influences endurance performance, ${ }^{54}$ but the effect on short-term high-intensity performance is still unclear. ${ }^{55}$ Thermoregulatory functions depend on sufficient body water. Consequently, losses in TBW can challenge the thermoregulatory system. A deficit of TBW with a BMc of $\geqslant 2 \%$ (dehydration) is the threshold for measurably altered thermoregulation. ${ }^{56}$

Recent evidence further complicates the assessment of hydration status, in that different hydration assessment markers may validly identify dehydration in one circumstance but not another. $^{37,47}$

\section{Limitations}

When interpreting data, one should be aware of the relative small number of studies. Although there are many studies about (de) hydration, some aspects differ substantially such as dehydration 
procedures and used hydration assessment markers. First, to achieve an euhydrated state before testing, all studies had to conduct a well-described hydration protocol and afterwards a well-described dehydration procedure (influenced by fluid restriction and/or physical activity). This limited the number of studies with tear fluid for example. Second, this review has focused on 'freely accessible' and direct evaluation of body fluids saliva, sweat and tear. Thus, saliva, sweat and tear could be directly compared to the other 'standardized' biochemical hydration assessment markers (see above) regarding osmolarity, osmomality ${ }^{20}$ and sodium concentration ${ }^{22}$ of body fluids. In particular, sweat as a hydration assessment marker was often indirectly evaluated.

\section{CONCLUSION}

In summary, the setting and the method of collecting respectively accessing body fluids determine the use of a biochemical hydration assessment marker. Compared to other body fluids (for example, blood) obtaining a sample of saliva is one of the simplest ways to collect body fluids. During exercise and heat exposures, saliva might be an effective index to evaluate hydration status but seems to be highly variable and should be carefully used as a substitute marker of other biochemical hydration assessment markers. The lack of a baseline measurement and the time-consuming collection of sweat makes it more difficult to evaluate dehydration and to make a statement about the hydration status at a particular time. The collection procedure of tears shows little discomfort to the participants and is easy to access. $\mathrm{TE}_{\mathrm{osm}}$ can evalute changes in hydration status and increase with dehydration and recorded changes in $\mathrm{BP}_{\text {osm }}$ with comparable utility to $U_{\mathrm{sg}}$. But with only two included studies, it has to be further determined whether $\mathrm{TE}_{\mathrm{osm}}$ is sensitive enough to evaluate dehydration at the individual level as its validity and reliability.

\section{CONFLICT OF INTEREST}

The authors declare no conflict of interest.

\section{ACKNOWLEDGEMENTS}

This study was supported by the 'Thim van der Laan' Foundation, Landquart, Switzerland.

\section{AUTHOR CONTRIBUTIONS}

Conceived and designed review: MV, RS, TV, EH, RC; analysed the data: MV, RS, TV, EH, MP, RC; wrote the paper: MV, RS, TV, EH, PC, FP, RC.

\section{REFERENCES}

1 Manz F. Hydration and disease. J Am Coll Nutr 2007; 26: 535-541.

2 Sawka MN, Burke LM, Eichner ER, Maughan RJ, Montain SJ, Stachenfeld NS. American College of Sports Medicine position stand. Exercise and fluid replacement. Med Sci Sport Exerc 2007; 39: 377-390.

3 Armstrong LE. Assessing hydration status: the elusive gold standard. J Am Coll Nutr 2007; 26: 575-584.

4 Cheuvront SN, Kenefick RW, Charkoudian N, Sawka MN. Physiologic basis for understanding quantitative dehydration assessment1-4. Am J Clin Nutr 2013; 97: 455-462.

5 El-Sharkawy AM, Sahota O, Lobo DN. Acute and chronic effects of hydration status on health. Nutr Rev 2015; 73: 97-109.

6 Trangmar SJ, González-Alonso J. New insights into the impact of dehydration on blood flow and metabolism during exercise. Exerc Sport Sci Rev 2017; 45: 146-153.

7 Baker LB, Lang JA, Kenney WL. Change in body mass accurately and reliably predicts change in body water after endurance exercise. Eur J Appl Physiol 2009; 105: 959-967.

8 Benton D, Jenkins KT, Watkins HT, Young HA. Minor degree of hypohydration adversely influences cognition: a mediator analysis. Am J Clin Nutr 2016; 104: 603-612.
9 Brooks GA, Fahey TD. Exercise Physiology: Human Bioenergetics and Its Applications. Wiley: New York, 1984.

10 Kristal-Bonch E, Blusman JG, Chaemovitz C, Cassuto U. Improved thermoregulations caused by forced water intake in human desert dwellers. Eur J Appl Physiol 1988; 57: 220-224.

11 Bergeron M. Keeping your players hydrated: what are the key points? High Perform Coach 2002; 2: 10-11.

12 Barr SI. Effects of dehydration on exercise performance. Can J Appl Physiol 1999; 24: $164-172$.

13 Cheuvront SN, Sawka MN. Hydration assessment of athletes. Sport Sci Exch 2005; 18: 1-6.

14 Casa DJ, Armstrong LE, Hillman SK, Montain SJ, Reiff RV, Rich BSE et al. National athletic trainers' association position statement: fluid replacement for athletes. J Athl Train 2000; 35: 212-224.

15 Cheuvront SN, Kenefick RW. Dehydration: physiology, assessment, and performance effects. Compr Physiol 2014; 4: 257-285

16 Cheuvront SN, Carter R 3rd, Montain SJ, Sawka MN. Daily body mass variability and stability in active men undergoing exercise-heat stress. Int J Sport Nutr Exerc Metab 2004; 14: 532-540.

17 Hamouti N, Coso JD, Avila A, Mora-Rodriguez R. Effects of athletes' muscle mass on urinary markers of hydration status. Eur J Appl Physiol 2010; 109: 213-219.

18 Koutedakis Y. Seasonal variation in fitness parameters in competitive athletes. Sport Med 1995; 19: 373-392.

19 Hamouti N, Del Coso J, Mora-Rodriguez R. Comparison between blood and urinary fluid balance indices during dehydrating exercise and the subsequent hypohydration when fluid is not restored. Eur J Appl Physiol 2013; 113: 611-620.

20 Cheuvront SN, Ely BR, Kenefick RW, Sawka MN. Biological variation and diagnostic accuracy of dehydration assessment markers. Am J Clin Nutr 2010; 92: 565-573.

21 Singh NR, Peters EM. Markers of hydration status in a 3-day trail running event. Clin J Sport Med Off J Can Acad Sport Med 2013; 23: 354-364.

22 Cosgrove SD, Black KE. Sodium supplementation has no effect on endurance performance during a cycling time-trial in cool conditions: a randomised crossover trial. J Int Soc Sports Nutr 2013; 10: 30.

23 Cheuvront SN, Kenefick RW, Sollanek KJ, Ely BR, Sawka MN. Water-deficit equation: Systematic analysis and improvement. Am J Clin Nutr 2013; 97: 79-85.

24 Manz F, Wentz A. 24-h hydration status: parameters, epidemiology and recommendations. Eur J Clin Nutr 2003; 57: 10-18.

25 Kavouras S. Assessing hydration status. Cur Opin Clin Nutr Metab Care 2002; 5: 519-524.

26 Shirreffs SM. Markers of hydration status. Eur J Clin Nutr 2003; 57: 6-9.

27 Ungaro CT, Reimel AJ, Nuccio RP, Barnes KA, Pahnke MD, Baker LB. Non-invasive estimation of hydration status changes through tear fluid osmolarity during exercise and post-exercise rehydration. Eur J Appl Physiol 2015; 115: 1165-1175.

28 Ely BR, Cheuvront SN, Kenefick RW, Sawka MN. Limitations of salivary osmolality as a marker of hydration status. Med Sci Sports Exerc 2011; 43: 1080-1084.

29 Oliver SJ, Laing SJ, Wilson S, Bilzon JLJ, Walsh NP. Saliva indices track hypohydration during $48 \mathrm{~h}$ of fluid restriction or combined fluid and energy restriction. Arch Oral Biol 2008; 53: 975-980.

30 Stewart R, Reed J, Zhong J, Morton K, Porter TL. Human hydration level monitoring using embedded piezoresistive microcantilever sensors. Med Eng Phys 2007; 29: 1084-1088.

31 Fortes MB, Diment BC, Di Felice U, Gunn AE, Kendall JL, Esmaeelpour M et al. Tear fluid osmolarity as a potential marker of hydration status. Med Sci Sports Exerc 2011; 43: 1590-1597.

32 Fortes MB, Owen JA, Raymond-Barker P, Bishop C, Elghenzai S, Oliver SJ et al. Is this elderly patient dehydrated? Diagnostic accuracy of hydration assessment using physical signs, Urine, and saliva markers. J Am Med Dir Assoc 2015; 16: 221-228.

33 Robertson GL. Abnormalities of thirst regulation. Kidney Int 1984; 25: 460-469.

34 Hew-Butler T, Hummel J, Rider BC, Verbalis JG. Characterization of the effects of the vasopressin V2 receptor on sweating, fluid balance, and performance during exercise. Am J Physiol Regul Integr Comp Physiol 2014; 307: 366-375.

35 Sreenbry LM. Saliva in health and disease: an appraisal and update. Int Dent $J$ 2000; 80: 140-161.

36 Walsh NP, Laing SJ, Oliver SJ, Montague JC, Walters R, Bilzon JLJ. Saliva parameters as potential indices of hydration status during acute dehydration. Med Sci Sports Exerc 2004; 36: 1535-1542.

37 Muñoz CX, Johnson EC, DeMartini JK, Huggins RA, McKenzie AL, Casa DJ et al. Assessment of hydration biomarkers including salivary osmolality during passive and active dehydration. Eur J Clin Nutr 2013; 67: 1257-1263.

38 Taylor NAS, Van Den Heuvel AMJ, Kerry P, McGhee S, Peoples GE, Brown MA et al. Observations on saliva osmolality during progressive dehydration and partial rehydration. Eur J Appl Physiol 2012; 112: 3227-3237.

39 Walsh RM, Noakes TD, Hawley JA, Dennis SC. Impaired high-intensity cycling performance time at low-levels of dehydration. Int J Sport Med 1994; 15: 392-398. 
40 Morgan RM, Patterson MJ, Nimmo MA. Acute effects of dehydration on sweat composition in men during prolonged exercise in the heat. Acta Physiol Scand 2004; 182: 37-43.

41 Smith DL, Shalmiyeva I, DeBlois J, Winke M. Use of salivary osmolality to assess dehydration. Prehospital Emerg Care 2012; 16: 128-135.

42 Perrier E, Demazières A, Girard N, Pross N, Osbild D, Metzger D et al. Circadian variation and responsiveness of hydration biomarkers to changes in daily water intake. Eur J Appl Physiol 2013; 113: 2143-2151.

43 Pross N, Demazières A, Girard N, Barnouin R, Santoro F, Chevillotte E et al. Influence of progressive fluid restriction on mood and physiological markers of dehydration in women. Br J Nutr 2012; 109: 313-321.

44 Ely BR, Cheuvront SN, Kenefick RW, Spitz MG, Heavens KR, Walsh NP et al. Assessment of extracellular dehydration using saliva osmolality. Eur J Appl Physiol 2014; 114: 85-92.

45 Armstrong LE, Maughan RJ, Senay LC, Shirreffs SM. Limitations to the use of plasma osmolality as a hydration marker. Am J Clin Nutr 2013; 98: 503-504.

46 Hooper L, Bunn DK, Abdelhamid A, Gillings R, Jennings A, Maas K et al. Water-loss (intracellular) dehydration assessed using urinary tests: How well do they work? Diagnostic accuracy in older people. Am J Clin Nutr 2016; 104: 121-131.

47 Armstrong LE, Kavouras SA, Walsh NP, Roberts WO. Diagnosing dehydration? Blend evidence with clinical observations. Curr Opin Clin Nutr Metab Care 2016; 19: 434-438.

48 Ship JA, Fischer DJ. The relationship between dehydration and parotid salivary gland function in young and older healthy adults. J Gerentol 1997; 52: 310-319.

49 Sawka MN, Cheuvront SN, Carter R. Human water needs. Nutr Rev 2005; 63: 30-39.
50 Lara B, Salinero JJ, Areces F, Ruiz-Vicente D, Gallo-Salazar C, Abian-Vicen J et al. Sweat sodium loss influences serum sodium concentration in a marathon. Scand J Med Sci Sports 2015; 27: 152-160.

51 Rolando M, Zierhut $\mathrm{M}$. The ocular surface and tear film and their dysfunction in dry eye disease. Surv Ophthalmol 2001; 45: 203-210.

52 Tiffany JM. Tears in health and disease. Eye 2003; 17: 923-926.

53 Maughan RJ. Investigating the associations between hydration and exercise performance: methodology and limitations. Nutr Rev 2012; 70: 128-131.

54 Maughan RJ, Shirreffs SM. Dehydration and rehydration in competitive sport. Scand J Med Sci Sport 2010; 20: 40-47.

55 Racinals S, Oksa J. Temperature and neuromuscular function. Scand J Med Sci Sport 2010; 20: 1-18.

56 Kenefick RW, Cheuvront SN. Physiological adjustments to hypohydration: impact on thermoregulation. Auton Neurosci Basic Clin 2016; 196: 47-51.

This work is licensed under a Creative Commons Attribution 4.0 International License. The images or other third party material in this article are included in the article's Creative Commons license, unless indicated otherwise in the credit line; if the material is not included under the Creative Commons license, users will need to obtain permission from the license holder to reproduce the material. To view a copy of this license, visit http://creativecommons.org/licenses/ by/4.0/

(c) The Author(s) 2018 